\title{
Multimedia \\ Signals and Systems
}

Srdjan Stanković

University of Montenegro, Faculty of Electrical Engineering

Irena Orović

University of Montenegro, Faculty of Electrical Engineering

\section{Ervin Sejdić}

University of Pittsburgh, Swanson School of Engineering, Department of Electrical and Computer Engineering 


\section{Content}

1 Mathematical transforms used for multimedia signal processing................5

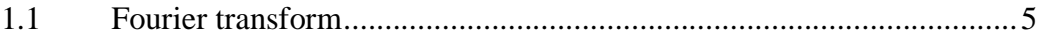

1.1.1 Discrete Fourier transform............................................................

1.1.2 Discrete cosine transform ........................................................ 10

1.2 Filtering in the frequency domain .................................................... 10

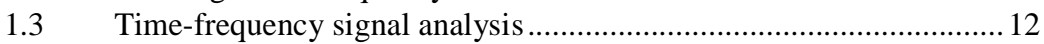

$1.4 \quad$ Ideal time-frequency representation ................................................. 13

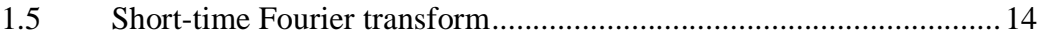

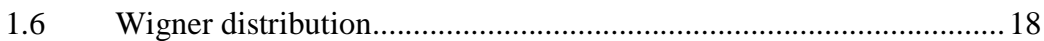

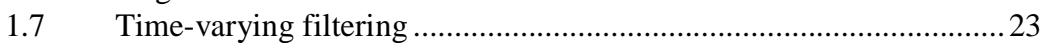

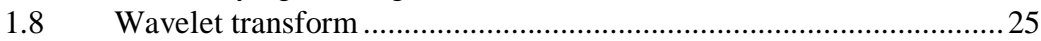

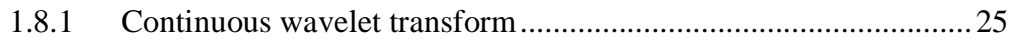

1.8.2 Wavelet transform with discrete wavelet functions ........................2 27

1.8.3 Wavelet Families ..................................................................... 28

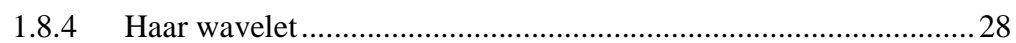

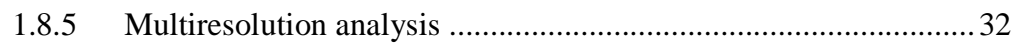

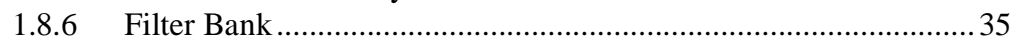

1.8.7 Daubechies orthogonal filters ...................................................... 37

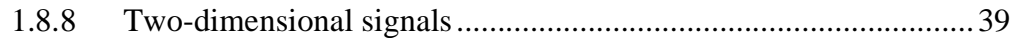

$1.9 \quad$ Signal decomposition using Hermite functions ................................... 43

1.9.1 One-dimensional signals and Hermite functions ............................4 44

1.9.2 Two-dimensional signals and two-dimensional Hermite functions 47

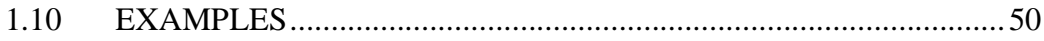

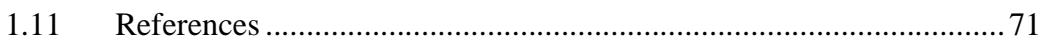

2 Digital audio

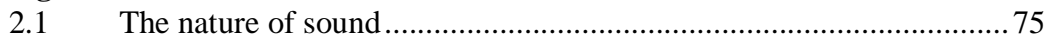

2.2 Development of systems for storing and playback of digital audio.... 77

2.3 Effects of sampling and quantization on the quality of audio signal.. 79

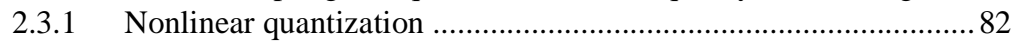

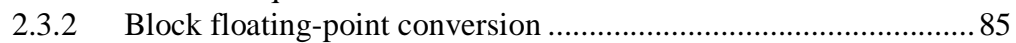

2.3.3 Differential Pulse Code Modulation (DPCM) ……........................ 85

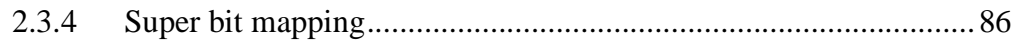

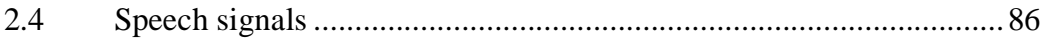

2.4.1 Linear model of speech production system ................................... 88 
2.5 Voice activity analysis and detectors ............................................ 91

2.5.1 Word endpoints detector......................................................... 96

2.6 Speech and music decomposition algorithm ................................... 98

2.6.1 Principal Components Analysis based on SVD ........................... 98

2.6.2 Components extraction by using the SVD and the S-method....... 99

$2.7 \quad$ Psychoacoustic effects................................................................... 104

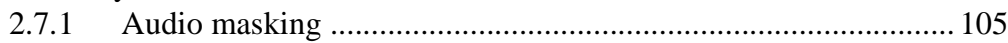

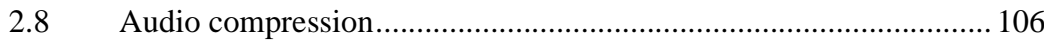

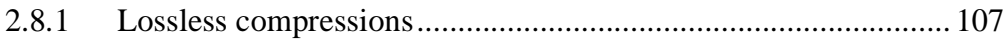

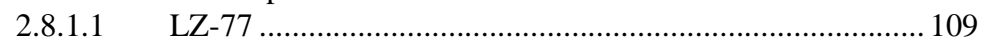

2.8.1.2 LZW coding ................................................................... 110

2.8.1.3 Huffman coding ............................................................. 114

2.8.2 Lossy compressions ............................................................. 115

2.8.2.1 Critical subbands and perceptual coding.......................... 116

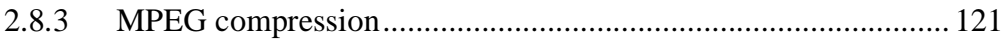

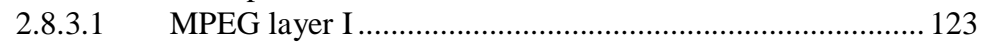

2.8.3.2 MPEG layer II.............................................................. 125

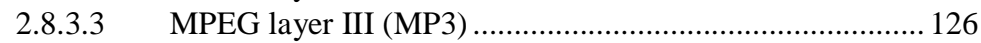

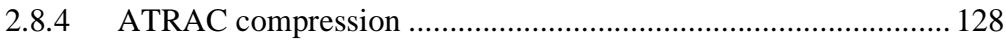

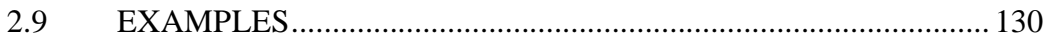

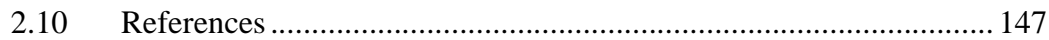

3 Storing and transmission of digital audio signals ................................. 149

$3.1 \quad$ Compact disc - CD ............................................................... 149

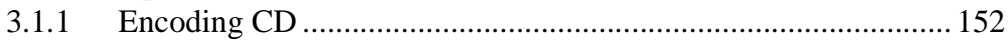

3.1.1.1 Cyclic Redundancy Check - CRC .................................... 152

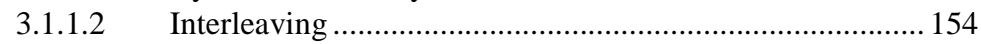

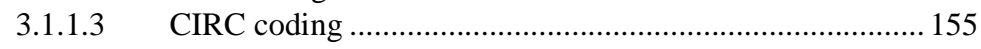

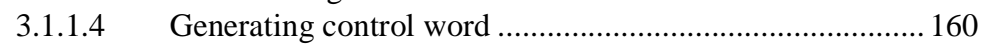

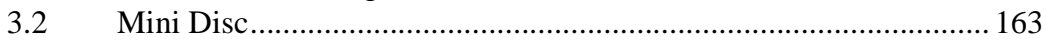

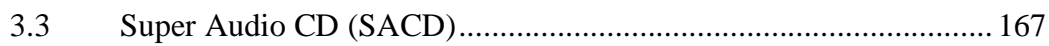

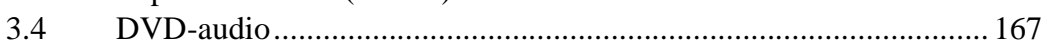

3.5 Principles of digital audio broadcasting - DAB ............................... 168

3.5.1 Orthogonal frequency-division multiplexing (OFDM) ............... 170

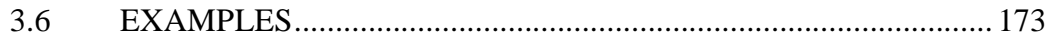

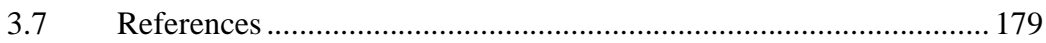

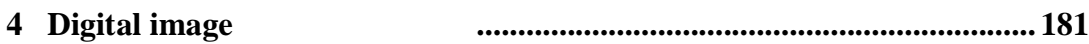

4.1 Fundamentals of digital image processing ................................... 181

4.2 Elementary algebraic operations with images ............................... 183

4.3 Basic geometric operations ...................................................... 185

4.4 The characteristics of the human eye ............................................ 187

4.5 Color models ................................................................................... 188

4.5.1 CMY, CMYK, YUV and HSV color......................................... 189

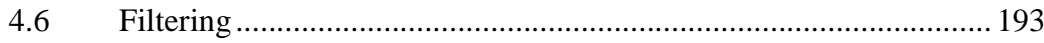


4.6.1 Noise probability distributions .................................................. 193

4.6.2 Filtering in the spatial domain ............................................... 195

4.6.2.1 Mean filter..................................................................... 195

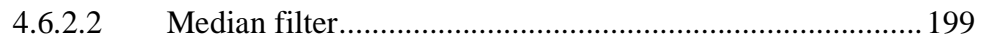

4.6.3 Filtering in the frequency domain.......................................... 203

4.6.4 Image sharpening................................................................ 204

4.6.5 Wiener filtering ..................................................................... 204

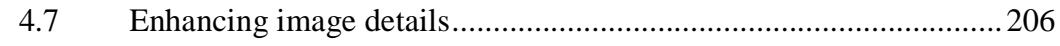

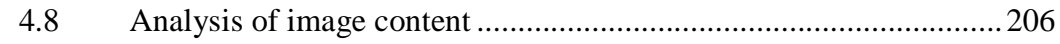

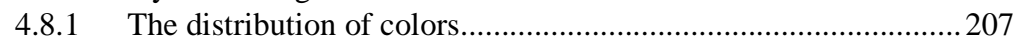

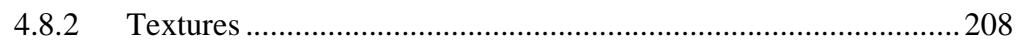

4.8.3 Co-occurrence matrix .............................................................. 210

4.8.4 Edge detection ..................................................................... 211

4.8.5 The condition of the global edge (Edge based representation - a

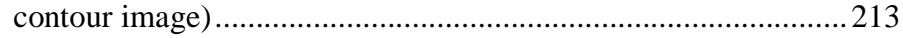

4.8.6 Dithering ............................................................................. 214

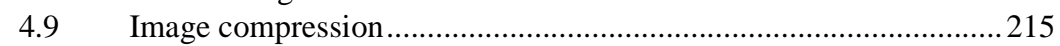

4.9.1 JPEG image compression algorithm......................................... 215

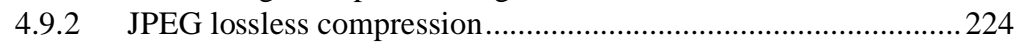

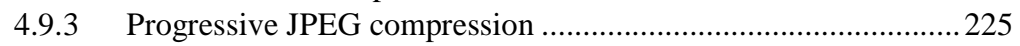

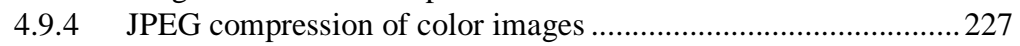

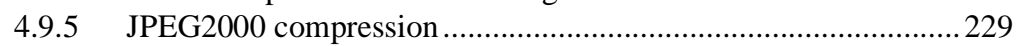

4.9.5.1 JPEG2000 Quantization .................................................. 234

4.9.5.2 Coding the regions of interest ............................................ 235

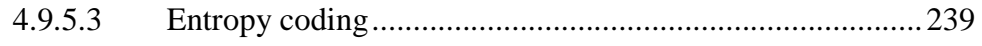

4.9.6 Fractal compression .............................................................. 246

4.9.7 Image reconstructions from projections ..................................... 247

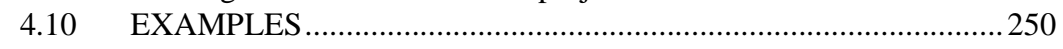

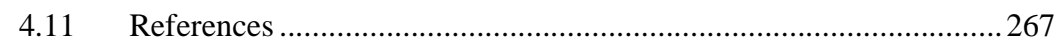

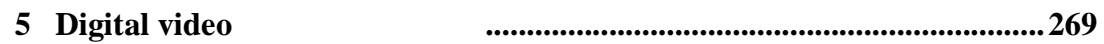

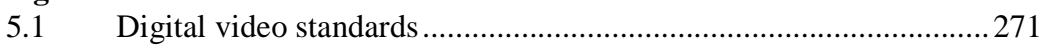

5.2 Motion parameters estimation in video sequences ........................... 272

5.3 Digital video compression ........................................................ 276

5.3.1 MPEG-1 video compression algorithm ..................................2276

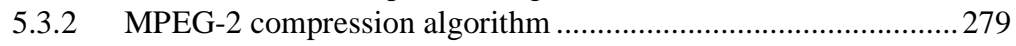

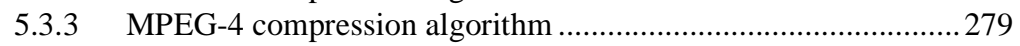

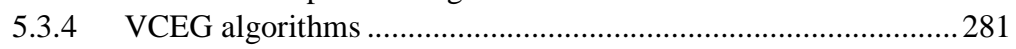

5.3.4.1 H.261 ................................................................ 281

5.3.4.2 H.263

5.3.4.3 H.264/MPEG4-AVC ..................................................... 283

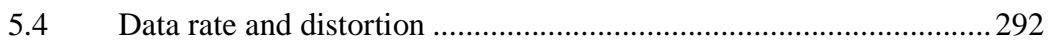

5.5 Communications protocols for multimedia data...............................2296

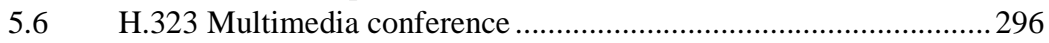

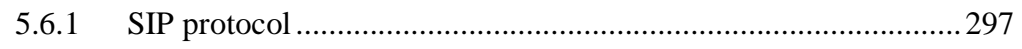




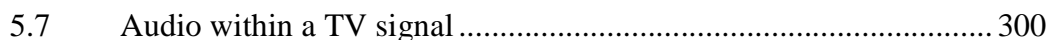

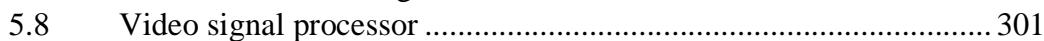

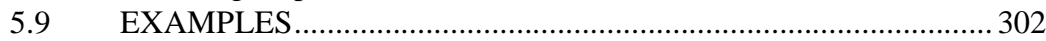

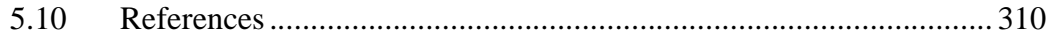

6 Compressive sensing $\quad$.................................................................313

6.1 The compressive sensing requirements ......................................... 315

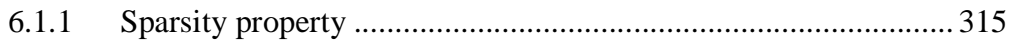

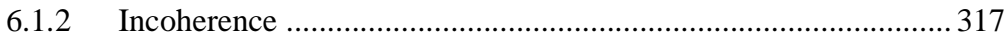

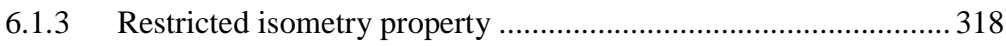

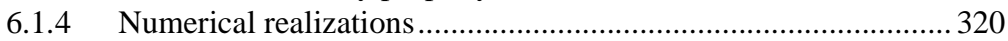

6.1.5 An example of using compressive sensing principles ................. 321

6.2 Applications of compressive sensing approach............................... 329

6.2.1 Multicomponent one-dimensional signal reconstruction ............. 329

6.2.2 Compressive sensing applied to image reconstruction ................. 333

6.2.3 Compressive sensing and sparse time-frequency analysis........... 337

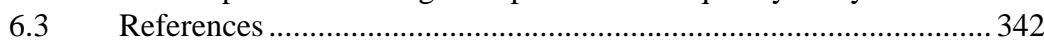

7 Digital Watermarking $\quad$..................................................................345

7.1 Classification of digital watermarking techniques .......................... 346

7.2 Common requirements considered in watermarking .........................348

7.3 Watermark embedding .............................................................. 350

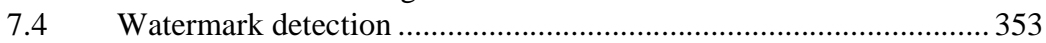

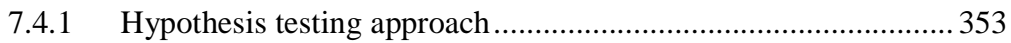

7.4.1.1 Additive white Gaussian model ....................................... 356

7.4.2 A class of locally optimal detectors......................................... 359

7.4.2.1 The most commonly used distribution functions and the corresponding detector forms .............................................. 359

7.4.3 Correlation coefficient and similarity measure ............................ 361

7.5 Examples of watermarking procedures ....................................... 362

7.5.1 Audio watermarking techniques ................................................ 362

7.5.1.1 Spread-spectrum watermarking ........................................ 362

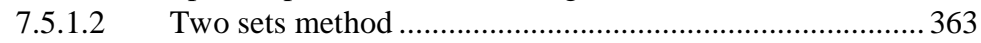

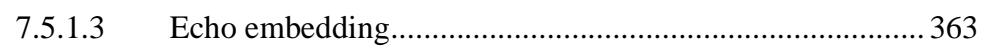

7.5.1.4 Watermarking based on the time-scale modifications ....... 364

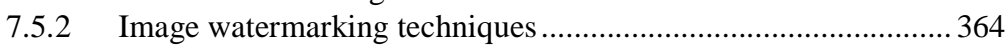

7.5.3 The procedure for watermarking of color images ...................... 365

7.5.4 An overview of some time-frequency based watermarking

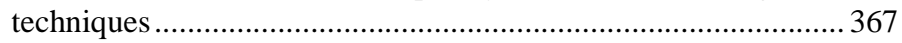

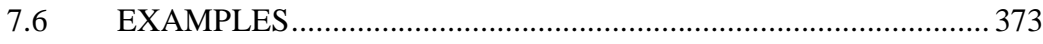

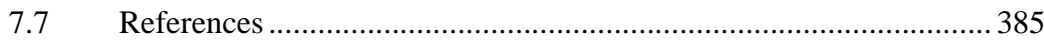

8 Multimedia signals and systems in telemedicine .....................................38.38

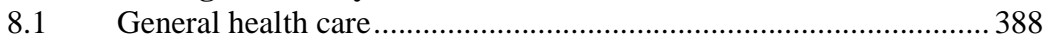

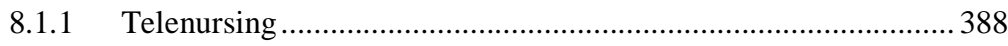




\begin{tabular}{|c|c|c|}
\hline \multicolumn{3}{|c|}{ 8.1.2 Telepharmacy } \\
\hline 8.1 .3 & Telerehabilitation. &. .389 \\
\hline 8.2 & Specialist health care. &. .391 \\
\hline 8.2 .1 & Telecardiology.. &. .391 \\
\hline 8.2 .2 & Teleradiology.. & 30 \\
\hline 8.2 .3 & Telesurgery .... & 34 \\
\hline 8.3 & References ...... & .39 \\
\hline
\end{tabular}

9 Multimedia communications......................................................................399

9.1 An overview of different networks types ...................................... 399

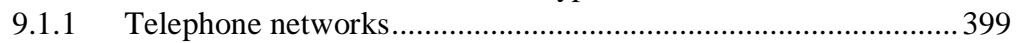

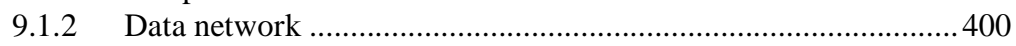

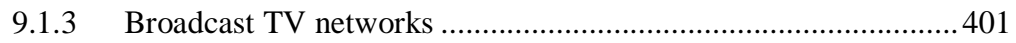

9.1.4 Integrated Services Digital Network (ISDN network) ................402

9.1.5 Multiservice broadband networks............................................... 404

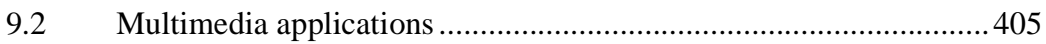

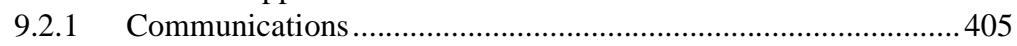

9.2.2 Interactive Internet applications ...............................................407

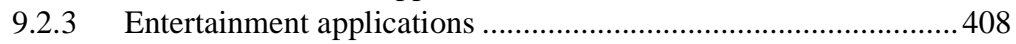

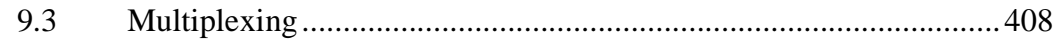

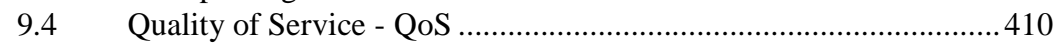

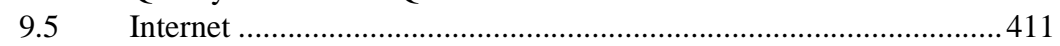

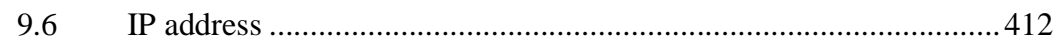

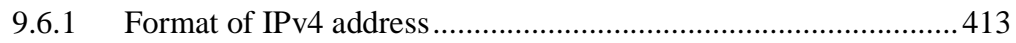

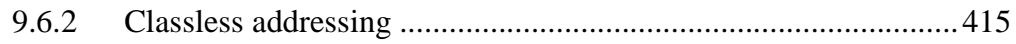

9.6.3 IPv6 address format ............................................................... 416

9.6.3.1 Specific IPv6 addresses............................................... 417

9.7 A protocol set for data transmission over the Internet (TCP / IP environment) .................................................................................... 419

9.7.1 IP protocol and IP datagram ............................................. 420

9.7.2 TCP protocol and connection-oriented service...........................422

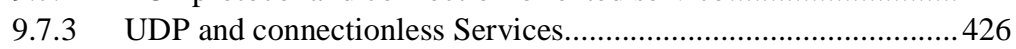

9.8 Higher order protocols................................................................ 428

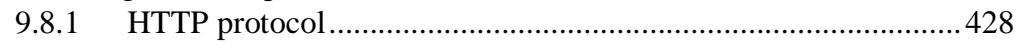

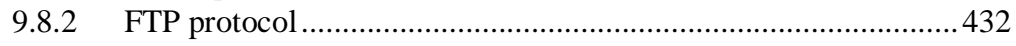

9.8.3 Other higher order protocols ............................................... 434

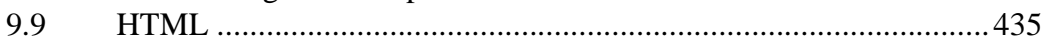

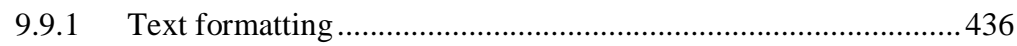

9.9.2 Background color and text color............................................... 437

9.9.3 Adding an image to HTML page ............................................ 438

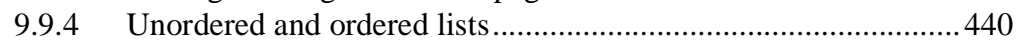

9.9.5 Links to other Web sites ........................................................... 441

9.9.6 Setting an anchor within a Web page .......................................... 442

9.9.7 Adding video content to a Web page............................................ 447

9.9.8 Creating and formatting tables................................................ 449 
9.9.9 Forms for data entry …......................................................... 451

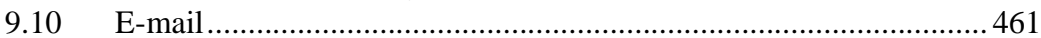

9.10.1 MIME - Multipurpose Internet Mail Extensions ................... 462

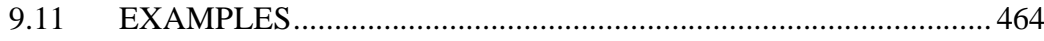

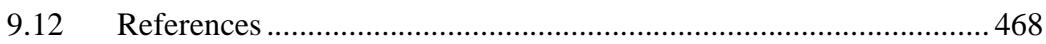




\section{Preface}

The book is composed as a combination of two intertwined areas: Multimedia signal processing and Multimedia systems. Note that multimedia signal processing is presented in a larger extent than in the standard books on fundamentals of multimedia systems.

Besides commonly used signal processing techniques, here we also consider the tools convenient for certain advanced applications that might inspire a reader for further improvement of the existing multimedia algorithms.

The book is divided into nine chapters. We should emphasize that the chapters on Mathematical transforms (Chapter 1), on Compressive sensing (Chapter 6), on Digital watermarking (Chapter 7) and on Telemedicine (Chapter 8) contain a more extensive and detailed analysis than it is usual in the existing literature on Multimedia systems. We especially note the chapter on Compressive sensing and its application in Multimedia, which is a completely new area that provides a new insight into the existing applications.

Chapters on Digital audio (Chapter 2), on Digital data storage and compression (Chapter 3), on digital image (Chapter 4), on Digital video (Chapter 5) and on Multimedia Communications (Chapter 9), basically follow the classical pattern of the content in this type of literature. However, the authors have put a considerable effort to enrich this material with a lot of comprehensive information, in order to facilitate the understanding of the presented text. These chapters also contain some new and, in our opinion, interesting recently published results. 
Each chapter ends with a section with worked out examples that may be useful for additional mastering and clarification of the presented material and for taking into account certain interesting applications. Beside basic examples, strictly associated with the presented theory, the book also contains some advanced applications that could be considered as a complement to the presented theory. A considerable number of Matlab codes is included in the examples, so that the reader can easily reconstruct most of the particular presented techniques.

Thus, the book basically contains a necessary material for understanding of the fundamentals of multimedia systems, and in that sense it may be used in the undergraduate courses. On the other hand, the parts related to the multimedia signal processing, together with the advanced techniques included in other chapters, may be used in the graduate courses as an appropriate literature related to the initial research.

Since this is the first edition, the authors are aware that, nevertheless all the efforts they have made to avoid the errors and ambiguities, they are practically unavoidable. Therefore, we will appreciate all the comments and suggestions to reduce these in the subsequent editions.

Finally, the authors gratefully acknowledge the useful and constructive suggestions of our colleagues during the preparation of the manuscript. We extend special gratitude to: Prof. Zdravko Uskoković, Prof. Ljubiša Stanković, Prof. Moeness Amin, Prof. Victor Sucic. Also, we are thankful to Dr Nikola Žarić, as well as to the PhD students Branka Jokanović and Andjela Draganić.

Podgorica, March 2012.

Authors 



\subsection{References}

[1] Amin MG, and Williams WJ (1998) High Spectral Resolution Time-Frequency Distribution kernels. IEEE Transactions on Signal Processing, 46(10): 2796-2804

[2] Bastiaans MJ, Alieva T, and Stankovic LJ (2002) On Rotated Time-Frequency Kernels. IEEE Signal Processing Letters, 9(11): 378-381

[3] Boashash B, and Ristic B (1998) Polynomial time-frequency distributions and time-varying higher order spectra: Application to the analysis of multicomponent FM signals and to the treatment of multiplicative noise. Signal Processing, 67(1): 1-23.

[4] Boashash B (2003) Time-Frequency Analysis and Processing. Elsevier, Amsterdam

[5] Cohen L (1989) Time-Frequency distributions-A review", Proc. IEEE, 77(7): 941-981.

[6] Daubechies I (1992) Ten Lectures on Wavelets. Society for industrial and applied mathematics

[7] Dudgeon D, Mersereau R (184) Multidimensional digital signal processing. Prentice Hall

[8] Fugal L (2009) Conceptual Wavelets in Digital Signal Processing. Space and Signal Technical Publishing

[9] González RC, Woods R (2008) Digital image processing. Prentice Hall.

[10] Hlawatsch F, Boudreaux-Bartels GF (1992) Linear and Quadratic Time-Frequency Signal Representations. IEEE Signal Processing Magazine, 9(2):21-67, April 1992

[11] Kortchagine D, and Krylov A (2000) Projection filtering in image processing. Proc. of Tenth International Conference on Computer Graphics and Applications (GraphiCon'2000): 42-45

[12] Kortchagine D, and Krylov A (2005) Image database retrieval by fast Hermite projection method. Proc. of Fifteenth International Conference on_Computer Graphics and Applications (GraphiCon'2005): 308-311 
[13] Krylov A, Kortchagine D (2006) Fast Hermite projection method. In Proc. of the Third International Conference on Image Analysis and Recognition (ICIAR 2006), 1: 329-338

[14] Mallat S (1999) A Wavelet Tour of Signal Processing. Academic Press, Second Edition

[15] Oppenheim A (1978) Applications of digital signal processing, Prentice Hall

[16] Orović I, Orlandić M, Stanković S, Uskoković Z (2011) A Virtual Instrument for Time-Frequency Analysis of Signals with Highly Non-Stationary Instantaneous Frequency. IEEE Transactions on Instrumentation and Measurements, 60(3):791803

[17] Orović I, Stanković S, Stanković LJ, Thayaparan T (2010) Multiwindow S-method for instantaneous frequency estimation and its application in radar signal analysis. IET Signal Processing, Special Issue on Time-Frequency Approach to Radar Detection, Imaging, and Classification, 4(4): 363-370

[18] Percival DB, Walden AT (2006) Wavelet Methods for Time Series Analysis, Cambridge University Press

[19] Radunović D (2005) Talasići. Akademska misao, Beograd

[20] Stanković LJ (1994) A Method for Time-Frequency Signal Analysis. IEEE Transactions on Signal Processing, 42(1): 225229

[21] Stanković LJ (1994) Multitime Definition of the Wigner Higher Order Distribution: L-Wigner Distribution. IEEE Signal Processing Letters, 1(7): 106-109

[22] Stanković S (2010) Time-Frequency Analysis and its Application in Digital Watermarking (Review paper). EURASIP Journal on Advances in Signal Processing, Special Issue on TimeFrequency Analysis and its Application to Multimedia signals, Vol. 2010, Article ID 579295, 20 pages

[23] Stanković S, Orović I, Krylov A (2010) Video Frames Reconstruction based on Time-Frequency Analysis and Hermite projection method. EURASIP Journal on Advances in Signal Processing, Special Issue on Time-Frequency Analysis and its Application to Multimedia signals, Article ID 970105, 11 pages 
[24] Stanković S, Orović I, Ioana C (2009) Effects of Cauchy integral formula on the precision of the IF estimation. IEEE Signal Processing Letters, 16(4): 327-330

[25] Stanković S, Stanković LJ (1997) An architecture for the realization of a system for time-frequency signal analysis. IEEE Transactions on Circuits and Systems Part II, 44(7): 600-604

[26] Stollnitz EJ, DeRose TD, and Salesin DH (1995) Wavelets for computer graphics: A primer, part 1. IEEE Computer Graphics and Applications, 15(3): 76-84

[27] Stollnitz EJ, DeRose TD, and Salesin DH (1995) Wavelets for computer graphics: A primer, part 2. IEEE Computer Graphics and Applications, 15(4): 75-85

[28] Strutz T (2009) Lifting Parameterization of the 9/7 Wavelet Filter Bank and its Application in Lossless Image Compression. ISPRA'09, Cambridge, UK: 161-166

[29] Strutz T (2009) Wavelet Filter Design based on the Lifting Scheme and its Application in Lossless Image Compression. WSEAS Transactions on Signal Processing, 5(2): 53-62

[30] Sydney Burus C, Gopinath RA, Guo H (1998) Introduction to Wavelets and Wavelet transforms: A Primer. Prentice-Hall, Inc

[31] Veterli M, Kovačević J (1995) Wavelets and subband coding. Prentice Hall

[32] Viswanath G, and Sreenivas TV (2002) IF estimation using higher order TFRs. Signal Processing, 82(2): 127-132 
Multimedia Signals and Systems

\subsection{References}

[1] Bosi M, Goldberg RE (2003) Introduction to digital audio coding and standards. Springer

[2] Chu WC (2003) Speech coding algorithms. Wiley

[3] Gibson J, Berger T, Lookabaugh T, Baker R, Lindbergh D (1998) Digital Compression for Multimedia: Principles \& Standards. Morgan Kaufmann

[4] Hankersson D, Greg AH, Peter DJ (1997) Introduction to Information Theory and Data Compression. CRC Press

[5] Hassanpour H, Mesbah M, Boashash B (2004) Time-Frequency Feature Extraction of Newborn EEG Seizure Using SVD-Based Techniques. EURASIP Journal on Applied Signal Processing, 16: 2544-2554

[6] Hoeg W, Lauterbach T (2003) Digital audio broadcasting: principles and applications of Digital Radio. John Wiley and Sons

[7] Kaplan R (1997) Intelligent Multimedia Systems. Willey

[8] Kovačević B, Milosavljević M, Veinović M, Marković M (2000) Robustna Digitalna Obrada Signala. Akademska misao, Beograd

[9] Maes J, Vercammen M, Baert L (2002) Digital audio technology, $4^{\text {th }}$ edn. In association with Sony, Focal Press

[10] Mataušek M, Batalov V (1980) A new approach to the determination of the glottal waveform. IEEE Transactions on Acoustics, Speech and Signal Processing, ASSP-28(6): 616-622

[11] Painter T (2000) Perceptual Coding of Digital Audio. Proceedings of the IEEE, 88(4): $451-513$

[12] Pan D (1995) A Tutorial on MPEG/Audio Compression. IEEE Multimedia, 2(2): 60-74

[13] Pohlmann KC (2005) Principles of Digital Audio. MCGrawHill

[14] Salomon D, Motta G, Bryant D (2009) Handbook of Data Compression. Springer

[15] Sayood K (2000) Introduction to Data Compression, $2^{\text {nd }}$ edn. Morgan Kaufmann. 
[16] Smith MT (1999) Audio Engineer's Reference Book, $2^{\text {nd }}$ edn. Focal Press

[17] Spanias A, Painter T, Atti V (2007) Audio signal processing and coding. Wiley-Interscience

[18] Stanković LJ (1994) A Method for Time-Frequency Signal Analysis. IEEE Transactions on Signal Processing 42(1): 225229

[19] Stanković S, Orović I (2010) Time-Frequency based Speech Regions Characterization and Eigenvalue Decomposition Applied to Speech Watermarking. EURASIP Journal on Advances in Signal Processing, Special Issue on Time-Frequency Analysis and its Application to Multimedia signals, Article ID 572748, Pages(s) 10 pages

[20] Steinmetz R (2000) Multimedia systems. McGrawHill

[21] Vetterli M, Kovačević J (1995) Wavelets and subband coding. Englewood Cliffs, NJ: Prentice-Hall

[22] Watkinson J (2001) The art of digital audio, $3^{\text {rd }}$ edn. Focal Press

[23] Watkinson J (2001) The MPEG Handbook, Focal Press

[24] Wong DY, Markel JD, Gray AH (1979) Least squares glottal inverse filtering from the acoustic speech waveform. IEEE Transactions on Acoustics, Speech and Signal Processing, ASSP-27(4) 


\subsection{References}

[1] Bahai A, Saltzberg BR, Ergen M (2004) Multi-Carrier Digital Communications, $2^{\text {nd }}$ edn. Springer

[2] Bosi M, Goldberg RE (2003) Introduction to digital audio coding and standards. Springer

[3] Frederiksen FB, Prasad R (2002) An overview of OFDM and related techniques towards development of future wireless multimedia communications. IEEE Radio and Wireless Conference, RAWCON 2002: 19-22

[4] Immink KAS (2002) A survey of codes for optical disk recording. IEEE Journal on Selected Areas in Communications, 19(4): 756-764

[5] Hoeg W, Lauterbach T (2003) Digital audio broadcasting: principles and applications of Digial Radio. John Wiley and Sons

[6] Lin TC, Truong TK, Chang HC, Lee HP (2011) A Future Simplification of Procedure for Decoding Nonsystematic ReedSolomon Codes Using the Berlekamp-Massey Algorithm. IEEE Transactions on Communications, 59(6): 1555-1562

[7] Maes J, Vercammen M, Baert L (2002) Digital audio technology, $4^{\text {th }}$ edn. In association with Sony, Focal Press

[8] Orović I, Zarić N, Stanković S, Radusinović I, Veljović Z (2011) Analysis of Power Consumption in OFDM Systems. Journal of Green Engineering 1(1): 477-489

[9] Painter T (2000) Perceptual Coding of Digital Audio. Proceedings of the IEEE, 88(4): $451-513$

[10]Roth R (2006) Introduction to Coding Theory. Cambridge University Press

[11] Shieh W, Djordjević I (2009) Orthogonal Frequency Division Multiplexing for Optical Communications. Academic Press

[12] Spanias A, Painter T, Atti V (2007) Audio signal processing and coding. Wiley-Interscience 
[13] Watkinson J (2001) The art of digital audio, $3^{\text {rd }}$ edn. Focal Press

[14] Wicker SB, Bhargava VK (1999) Reed-Solomon codes and its Applications. John Wiley and Sons 
Multimedia Signals and Systems

\subsection{References}

[1] Askelof J, Larsson Carlander M, Christopoulos C (2002) Region of interest coding in JPEG2000. Signal processing: Image communication, 17 (2002): 105-111

[2] Baret HH, Myers K (2004) Foundation of image science. John Willey and Sons

[3] Bednar J, Watt T (1984) Alpha-trimmed means and their relationship to median filters. IEEE Transactions on Acoustics, Speech and Signal Processing, 32(1): 145-153

[4] Daubechies I (1992) Ten Lectures on Wavelets. Society for industrial and applied mathematics

[5] Djurovic I (2006) Digitalna obrada slike. Univerzitet Crne gore, Elektrotehnicki fakultet Podgorica

[6] Dyer M, Taubman D, Nooshabadi S, Kumar Gupta A (2006) Concurrency Techniques for Arithmetic Coding in JPEG2000. IEEE Transactions on Circuits and Systems I: 53(6): 1203-1213

[7] Fisher Y. (Ed.) (1995) Fractal Image Compression: Theory and Application to Digital Images. Springer Verlag, New York

[8] Furth B, Smoliar S, Zhang H (1996) Video and image processing in Multimedia systems. Kluwer Academic Publishers

[9] González RC, Woods R (2008) Digital image processing. Prentice Hall

[10] Kato T, Kurita T, Otsu N, Hirata KA (1992) Sketch retrieval method for full color image database-query by visual example. Proceedings 11th IAPR International Conference on Pattern Recognition, vol I, Computer Vision and Applications: 530-533

[11] Khan MI, Jeoti V, Khan MA (2010) Perceptual encryption of JPEG compressed images using DCT coefficients and splitting of DC coefficients into bitplanes. International Conference on Intelligent and Advanced Systems (ICIAS): 1-6

[12] Man H, Docef A, Kossentini F (2005) Performance Analysis of the JPEG2000 image coding standard. Multimedia Tools and Applications Journal, 26(1): 27-57

[13] Percival DB, Walden AT (2006) Wavelet Methods for Time Series Analysis. Cambridge University Press 
[14] Qi YL (2009) A Relevance Feedback Retrieval Method Based on Tamura Texture. Second International Symposium on Knowledge Acquisition and Modeling, KAM '09: 174-177

[15] Rabbani M, Joshi B (2002) An overview of the JPEG2000 still image compression standard. Signal Processing: Image Communication, 17(1): 3-48

[16] Salomon D, Motta G, Bryant D (2009) Handbook of Data Compression. Springer

[17] Stanković LJ (1990) Digitalna Obrada Signala. Naučna knjiga

[18] Steinmetz R (2000) Multimedia systems. McGrawHill.

[19] Stollnitz EJ, DeRose TD, Salesin DH (1995) Wavelets for computer graphics: A primer, part 1. IEEE Computer Graphics and Applications, 15(3): 76-84

[20] Stollnitz EJ, DeRose TD, and Salesin DH (1995) Wavelets for computer graphics: A primer, part 2. IEEE Computer Graphics and Applications, 15(4): 75-85

[21] Strutz T (2009) Lifting Parameterisation of the 9/7 Wavelet Filter Bank and its Application in Lossless Image Compression. ISPRA'09: 161-166

[22] Strutz T (2009) Wavelet Filter Design based on the Lifting Scheme and its Application in Lossless Image Compression. WSEAS Transactions on Signal Processing, 5(2): 53-62

[23] Tamura H, Shunji M, Takashi Y (1978) Textural Features Corresponding to Visual Perception. IEEE Transactions on Systems, Man and Cybernetics, 8(6): 460-473

[24] Taubman D, Marcellin M (2002) JPEG2000: Standard for Interactive Imaging. Proceedings of the IEEE, 90: 1336-1357

[25] Thyagarajan KS (2006) Digital image processing with application to digital cinema. Elsevier Focal Press

[26] T.81: Information technology - Digital compression and coding of continuous-tone still images - Requirements and guidelines

[27] Veterli M, Kovačević J (1995) Wavelets and subband coding. Prentice Hall

[28] Wagh KH, Dakhole PK, Adhau VG (2008) Design and Implementation of JPEG2000 Encoder using VHDL. Proc. of the World Congress on Engineering, vol. I WCE 2008

[29] Young I, Gerbrands J, Vliet LV (2009) Fundamentals of Image Processing. Delft University of Technology 


\subsection{References}

[1] Akbulut O, Urhan O, Ertürk S (2006) Fast Sub-pixel Motion Estimation by Means of One-Bit Transform. Proc. ISCIS: 503510

[2] Djurović I, Stanković S (2003) Estimation of time-varying velocities of moving objects in video-sequences by using timefrequency representations. IEEE Trans. on Image Processing, 12(5): 550-562

[3] Djurović I, Stanković S, Oshumi A, Ijima H (2004) Motion parameters estimation by new propagation approach and timefrequency representations. Signal Processing - Image Communications, 19(8): 755-770

[4] Furth B, Smoliar S, Zhang H (1996) Video and image processing in Multimedia systems. Kluwer Academic Publishers

[5] Grob B, Herdon C (1999) Basic television and video systems. McGraw-Hill

[6] Karczewicz M, Kurceren R (2001) A Proposal for SP-Frames. ITU-T Video Coding Experts Group Meeting, Eibsee, Germany, Doc. VCEG-L-27

[7] Karczewicz M, Kurceren R (2003) The SP- and SI-Frames Design for H.264/AVC. IEEE Transactions on Circuits and Systems for Video Technology, 13(7): 637-644

[8] Kaup A (1999) Object-based texture coding of moving video in MPEG-4. IEEE Trans. Circuits and Systems for Video Technology, 9 (1): 5-15

[9] Lie WN, Yeh HC, Lin TCI, Chen CF (2005) HardwareEfficient Computing Architecture for Motion Compensation Interpolation in H.264 Video Coding. IEEE International Symposium on Circuits and Systems: 2136-2139

[10] Malvar HS, Hallapuro A, Karczevicz M, Kerofsky L (2003) Low-complexity transform and quantization in H.264/AVC. IEEE Transactions on Circuits and Systems for Video Technology, 13(7): 598-603 
[11] Marpe D, Wiegand T, Sullivan GJ (2006) The H.264/MPEG4 advanced video coding standard and its applications. IEEE Communications Magazine, 44(8): 134-143

[12] Nisar H, Choi TS (2009) Fast and efficient fractional pixel motion estimation for H.264/AVC video coding. International Conference on Image Processing (ICIP 2009): 1561 - 1564

[13] Richardson I (2010) The H.264 Advanced Video Compression Standard. John Wiley and Sons

[14] Richardson I (2002) Video codec design. Wiley

[15] Salomon D, Motta G, Bryant D (2009) Handbook of Data Compression. Springer

[16] Stanković S, Djurović I (2001) Motion parameter estimation by using time frequency representations. Electronics Letters, 37(24): 1446-1448

[17] Stanković S, Orović I, Krylov A (2010) Video Frames Reconstruction based on Time-Frequency Analysis and Hermite projection method. EURASIP Journal on Advances in Signal Processing, Special Issue on Time-Frequency Analysis and its Application to Multimedia signals, Article ID 970105, 11 pages

[18] Steinmetz R (2000) Multimedia systems. McGrawHill

[19] Sullivan GJ, Wiegand T (2005) Video Compression - From Concepts to the H.264/AVC Standard. Proceedings of the IEEE, 93(1): 18-31

[20] Sullivan GJ, Topiwala P, Luthra A (2004) The H.264/AVC Advanced Video Coding Standard: Overview and Introduction to the Fidelity Range Extensions. SPIE Conference on Applications of Digital Image Processing, 454 (2004), http://dx.doi.org/10.1117/12.564457

[21] Wiegand T, Sullivan GJ, Bjontegaard G, Luthra A (2003) Overview of the H.264/AVC video coding standard. IEEE Transactions on Circuits and Systems for Video Technology, 13(7): 560-576 


\subsection{References}

[1] Ahmad F, Amin MG, Through-the-wall human motion indication using sparsity-driven change detection. IEEE Transactions on Geoscience and Remote Sensing, In Press

[2] Baraniuk R (2007) Compressive sensing. IEEE Signal Processing Magazine, 24(4): 118-121

[3] Candès E (2006) Compressive Sampling. Int. Congress of Mathematics, 3: 1433-1452

[4] Candès E, Romberg J (2007) Sparsity and incoherence in compressive sampling. Inverse Problems, 23(3): 969-985, 2007

[5] Candès E, Romberg J, Tao T (2006) Robust uncertainty principles: Exact signal reconstruction from highly incomplete frequency information. IEEE Transactions on Information Theory, 52(2): 489 - 509

[6] Candès E, Wakin M (2008) An introduction to compressive sampling. IEEE Signal Processing Magazine, 25(2): 21 - 30

[7] Chartrand R (2007) Exact reconstructions of sparse signals via nonconvex minimization. IEEE Signal Processing Letters, 14(10): 707-710

[8] Chen SS, Donoho DL (1999) Saunders MA, Atomic decomposition by Basis Pursuit. SIAM Journal on Scientific Computing, 20(1): 33-61, 1999

[9] Donoho D (2006) Compressed sensing. IEEE Trans. on Information Theory, 52(4): 1289 - 1306

[10] Donoho DL, Tsaig Y, Drori I, Starck JL (2007) Sparse solution of underdetermined linear equations by stagewise orthogonal matching pursuit. IEEE Transaction on Information Theory, 58(2): 1094-1121

[11] Duarte M, Wakin M, Baraniuk R (2005) Fast reconstruction of piecewise smooth signals from random projections. SPARS Workshop

[12] Duarte M, Davenport M, Takhar D, Laska J, Sun T, Kelly K, Baraniuk R (2008) Single-pixel imaging via compressive sampling. IEEE Signal Processing Magazine, 25(2): 83 - 91 
[13] Flandrin P, P. Borgnat P (2010) Time-Frequency Energy Distributions Meet Compressed Sensing. IEEE Transactions on Signal Processing, 8(6): 2974-2982

[14] Fornasier M, Rauhut H (2011) Compressive sensing. (Chapter in Part 2 of the Handbook of Mathematical Methods in Imaging (O. Scherzer Ed.). Springer

[15] Gurbuz AC, McClellan JH, Scott, Jr. WR (2009) A Compressive Sensing Data Acquisition and Imaging Method for Stepped Frequency GPRs. IEEE Transactions Geoscience and Remote Sensing, 57(7): 2640-2650

[16] Jokar S, Pfetsch ME (2007) Exact and approximate sparse solutions of underdetermined linear equations. (Preprint, 2007)

[17] Laska J, Davenport M, Baraniuk R (2009) Exact signal recovery from sparsely corrupted measurements through the pursuit of justice. Asilomar Conf. on Signals, Systems, and Computers

[18] L1-MAGIC: http://users.ece.gatech.edu/ justin/11magic/

[19] Peyré G (2010) Best basis compressed sensing. IEEE Transactions on Signal Processing, 58(5): 2613-2622

[20] Romberg J (2008) Imaging via compressive sampling. IEEE Signal Processing Magazine, 25(2): $14-20$

[21] Saab R, Chartrand R, Yilmaz Ö (2008) Stable sparse approximation via nonconvex optimization. IEEE Int. Conf. on Acoustics, Speech, and Signal Processing (ICASSP)

[22] Saligrama V, Zhao M (2008) Thresholded basis pursuit: Quantizing linear programming solutions for optimal support recovery and approximation in compressed sensing. (Preprint, 2008)

[23] Stankovic LJ (1996) The auto-term representation by the reduced interference distributions; The procedure for a kernel design. IEEE Trans. on Signal Processing, 44(6):1557-1564

[24] Stanković S, Zarić N, Orović I, Ioana C (2008) General form of time-frequency distribution with complex-lag argument. Electronics Letters, 44(11): 699-701

[25] Tropp J, Gilbert A (2007) Signal recovery from random measurements via orthogonal matching pursuit. IEEE Trans. on Information Theory, 53(12): 4655-4666

[26] Tropp J, Needell D (2008) CoSaMP: Iterative signal recovery from incomplete and inaccurate samples. Appl. Comput. Harmon. Anal., pages 30 
[27] Yoon Y, Amin MG (2008) Compressed sensing technique for high-resolution radar imaging. Proc. SPIE, 6968: 6968A69681A-10 


\subsection{References}

[1] Al-khassaweneh M, Aviyente S (2005) A Time-Frequency Based Perceptual and Robust Watermarking Scheme. Proc. of EUSIPCO 2005

[2] Barni M, Bartolini F (2004) Watermarking Systems Engineering. Marcel Dekker, Inc, New York

[3] Briassouli A, Strintzis MG (2004) Locally Optimum Nonlinearities for DCT Watermark Detection. IEEE Transactions on Image Processing (13)12:1604-1618

[4] Cox IJ, Miller ML, Bloom JA (2002) Digital Watermarking, Academic Press

[5] Djurović I, Stanković S, Pitas I (2001) Digital Watermarking in the Fractional Fourier Transformation Domain. Journal of Network and Computer Applications. Academic Press, 24(2): 167173

[6] Esmaili S, Krishnan S, Raahemifar K (2003) Audio watermarking time-frequency characteristics. Canadian Journal of Electrical and Computer Engineering, 28(2): 57 - 61

[7] Foo SW, Ho SM, Ng LM (2004) Audio watermarking using time-frequency compression expansion. Proc. of the Int. Symp. on Circuits and Systems, ISCAS 04, 3: III - 201-4

[8] Hernandez JR, Amado M, Perez Gonzales F (2000) DCTdomain watermarking techniques for still images: Detector performance analysis and a new structure. IEEE Transactions on Image Processing, 9: 55-68

[9] Kirovski D, Malvar HS (2003) Spread-spectrum watermarking of audio signals. IEEE Transactions on Signal Processing, 51(4): 1020-1033

[10] Mobasseri BG, Zhang Y, Amin MG, Dogahe BM (2005) Designing robust watermarks using polynomial phase exponentials. Proc. of Acoustics, Speech, and Signal Processing (ICASSP '05), vol. 2: ii/833- ii/836

[11] Muharemagić E, Furht B (2006) Survey of Watermarking Techniques and Applications. Chapter 3 in Multimedia 
Watermarking Techniques and Applications, B. Furht and D. Kirovski, editor, Auerbach Publication: 91-130

[12] Nikolaidis A, Pitas I (2003) Asymptotically optimal detection for additive watermarking in the DCT and DWT domains. IEEE Transactions on Image Processing, 12(5): 563-571

[13] Proceedings of the IEEE: Special Issue on Identification and Protection of Multimedia Information, vol. 87, July 1999

[14] Stankovic LJ, Stankovic S, Djurovic I (2000) Space/SpatialFrequency Based Filtering. IEEE Transaction on Signal Processing, 48(8): 2343-2352

[15] Stanković S, Djurović I, Herpers R, Stanković LJ (2003) An approach to the optimal watermark detection. AEUE International Journal of Electronics and Communications, 57(5): 355357

[16] Stanković S, Djurović I, Pitas I (2001) Watermarking in the space/spatial-frequency domain using two-dimensional RadonWigner distribution. IEEE Transactions on Image Processing, 10: $650-658$

[17] Stanković S, Orović I, Žarić N (2008) Robust watermarking procedure based on JPEG-DCT image compression. Journal of Electronic Imaging, 17(4), Page(s) 043001

[18] Stanković S, Orović I, Žarić N (2010) An Application of Multidimensional Time-Frequency Analysis as a base for the Unified Watermarking Approach. IEEE Transactions on Image Processing, 19(2): 736-745

[19] Stanković S (2000) About Time-Variant Filtering of Speech Signals with Time-Frequency Distributions for Hands-Free Telephone Systems. Signal Processing, 80(9): 1777-1785

[20] Stanković S, Orović I, Žarić N (2008) Robust speech watermarking in the time-frequency domain. EURASIP Journal on Advances in Signal Processing, Issue ID 519206

[21] Steinebach M, Dittmann J (2003) Watermarking-based digital audio data authentication. EURASIP Journal on Applied Signal Processing, 2003(10): 1001-1015

[22] Wickens TD (2002) Elementary Signal Detection Theory. Oxford Univ. Press 


\subsection{References}

[1] Anvari M (2007) Telesurgery: Remote Knowledge Translation in Clinical Surgery. World Journal of Surgery, 31(8): 15451550

[2] Arnaert A, Delesie L (2001) Telenursing for the elderly. The case for care via video-telephony. Journal of Telemedicine and Telecare, 7(6): 311-316

[3] Barneveld Binkhuysena FH, Ranschaert ER (2011) Teleradiology: Evolution and concepts. European Journal of Radiology, 78(2): 205-209

[4] Brunetti ND, Amodio G, De Gennaro L, Dellegrottaglie G, Pellegrino PL, Di Biase M, Antonelli G (2009) Telecardiology applied to a region-wide public emergency health-care service. Journal of Thrombosis and Thrombolysis, 28(1): 23-30

[5] Bynum A, Hopkins D, Thomas A, Copeland N, Irwin C (2001) The Effect of Telepharmacy Counseling on Metered-Dose Inhaler Technique among Adolescents with Asthma in Rural Arkansas. Telemedicine Journal and E-Health, 7(3): 207-217

[6] Chan WM, Hjelm NM (2001) The role of telenursing in the provision of geriatric outreach services to residential homes in Hong Kong. Journal of Telemedicine and Telecare, 7(1): 38-46

[7] Friesner DL, Scott DM, Rathke AM, Peterson CD, Anderson HC (2011) Do remote community telepharmacies have higher medication error rates than traditional community pharmacies? Evidence from the North Dakota Telepharmacy Project. Journal of the American Pharmacists Association, 51(5): 580-590

[8] Garrelts JC, Gagnon M, Eisenberg C, Moerer J, Carrithers J (2010) Impact of Telepharmacy in a Multihospital Health System. American Journal of Health-System Pharmacy, 67(17): 1456-1462

[9] Giansanti D, Morelli S, Maccioni G, Costantini G (2009) Toward the Design of a Wearable System for Fall-Risk Detection in Telerehabilitation. Telemedicine and e-Health, 15(3): 296299 
[10] Hagan L, Morin D, Lepine R (2000) Evaluation of Telenursing Outcomes: Satisfaction, Self-Care Practices, and Cost Savings. Public Health Nursing, 17(4): 305-313

[11] Hermann VH, Herzog M, Jordan R, Hofherr K, Levine P, Page SJ (2010) Telerehabilitation and Electrical Stimulation: An Occupation-Based, Client-Centered Stroke Intervention. The American Journal of Occupational Therapy, 64(1): 73-81

[12] Jerant AF, Azari R, Martinez C, Nesbitt TS (2003) A Randomized Trial of Telenursing to Reduce Hospitalization for Heart Failure: Patient-Centered Outcomes and Nursing Indicators. Home Health Care Services Quarterly, 22(1): 1-20

[13] Jönsson AM, Willman A (2009) Telenursing In Home Care Services: Experiences of Registered Nurses. Electronic Journal of Health Informatics, 4(1): e9-1-7

[14] Kairy D, Lehoux P, Vincent C, Visintin M (2009) A systematic review of clinical outcomes, clinical process, healthcare utilization and costs associated with telerehabilitation. Disability and Rehabilitation, 31(6): 427-447

[15] Katz ME (2010) Pediatric teleradiology: the benefits. Pediatric Radiology, 40(8): 1345-1348

[16] Lai JCK, Woo J, Hui E, Chan WM (2004) Telerehabilitation - a new model for community-based stroke rehabilitation. Journal of Telemedicine and Telecare, 10(4): 199-205

[17] Lam AY, Rose D (2009) Telepharmacy services in an urban community health clinic system. Journal of the American Pharmacists Association, 49(5): 652-659

[18] Mitchell JR, Sharma P, Modi J, Simpson M, Thomas M, Hill MD, Goyal M (2011) A Smartphone Client-Server Teleradiology System for Primary Diagnosis of Acute Stroke. Journal of Medical Internet Research, 2: e31

[19] Nikus K, Lähteenmäkib J, Lehto P, Eskola M (2009) The role of continuous monitoring in a 24/7 telecardiology consultation service - a feasibility study. Journal of Electrocardiology, 42(6): 473-480

[20] Pappasa Y, Sealeb C (2010) The physical examination in telecardiology and televascular consultations: A study using conversation analysis. Patient Education and Counseling, 81(1): $113-118$ 
[21] Peterson CD, Anderson HC (2004) The North Dakota Telepharmacy Project: Restoring and Retaining Pharmacy Services in Rural Communities. The Journal of pharmacy technology, 20(1): 28-39

[22] Wakefield DS, Ward MM, Loes JL, O’Brien J, Sperry L (2010) Implementation of a telepharmacy service to provide round-theclock medication order review by pharmacists. American Journal of Health-System Pharmacy, 67(23): 2052-2057

[23] Ward E, Crombie J, Trickey M, Hill A, Theodoros D, Russell T (2009) Assessment of communication and swallowing postlaryngectomy: a telerehabilitation trial. Journal of Telemedicine and Telecare, 15(5): 232-237

[24] Whitten P, Mair F, Collins B (2001) Home telenursing in Kansas: patients' perceptions of uses and benefits. Journal of Telemedicine and Telecare, 3(1): 67-69

[25] Winters JM (2002) Telerehabilitation research: Emerging Opportunities. Annual Review of Biomedical Engineering, 4: 287320 


\subsection{References}

[1] Black UD (2000) Internet Architectures: An Introduction to IP Protocols. Prentice Hall

[2] Doyle J (1998) Routing TCP/IP Volume I (CCIE Professional Development). Cisco Press

[3] Halsall F (2001) Multimedia communications: applications, networks, protocols, and standards. Addison-Wesley

[4] Forouzan BA, Fegan SC (2003) Data Communications and Networking. McGraw-Hill

[5] Johnston AB, Sinnreich H (2006) Internet communications using SIP: delivering VoIP and multimedia services with Session Initiation Protocol. John Wiley \& Sons

[6] Keshav S (1997) An engineering approach to computer networking: ATM networks, the internet, and the telephone network. Addison-Wesley

[7] Korpi M, Kumar V, Sengodan S (2001) IP Telephony with H.323: Architectures for Unified Networks and Integrated Services. John Wiley \& Sons

[8] Kraig G (2007) The Essential Guide to CSS and HTML Web Design. Springer

[9] Niederst J, Niederst Robbins J (2001) Web design in a nutshell: a desktop quick reference. O'Reilly Media, Inc.

[10] Ohm JR (2004) Multimedia Communication Technology Representation, Transmission and Identification of Multimedia Signals. Springer

[11] Sulkin A (2002) PBX Systems for IP Telephony. McGraw-Hill Professional

[12] Wright DJ (2001) Voice Over Packet Networks. John Wiley \& Sons 